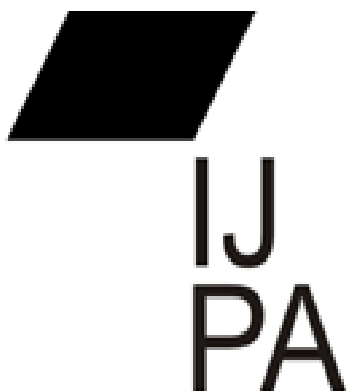

ISSN $2460=0369$

\section{ANALISIS AKTOR YANG BERPERAN DAN MEMPENGARUHI IMPLEMENTASI KEBIJAKAN TATA RUANG : STUDI DI KABUPATEN PANDEGLANG}

\author{
AGUS LUKMAN HAKIM \\ Ilmu Administrasi Niaga, \\ Sekolah Tinggi Ilmu Administrasi Banten \\ aguslukman.hakim@stiabanten.ac.id
}

Abstract: Pandeglang Regency of Banten Province has stipulated Perda no. 03 of 2011 on Spatial Pandeglang District 2011-2031. Post-implementation of the law has not had an impact on the development of Pandeglang Regency. This study aims to analyze the actors who fought and in the Implementation of Perda RTRW. This study uses primary data, questionnaires and interviews as well as existing data. Qualitative descriptive approach, with stakeholder analysis tools and Content. The result of the research is the interested actors and necessary in the implementation of spatial policy in Pandeglang regency is the regent. Functions used for BAPPEDA, Department of Labor and Spatial Planning, Department of Investment and One Stop Integrated Service Permit. Furthermore, the Office of the Environment, the Department of Fisheries, the Department of Tourism, the Office of Agriculture, the Office of Trade Industry, the Office of Settlement, the Residential and Land Areas, Commission I of the Pandeglang Parliament, the Transportation Department and the Civil Service Police Unit. The key player or key player in the policy implementation is the Regent and the Agency / Agency concerned. The actors who have a small role and great influence in the spatial policies in Pandeglang, namely Investors, Journalists, NGOs are categorized in the Contest Setter (supporters). The role of small role and impression is mass media that is categorized as a crowd (other followers). Implementation of spatial policy is highly dependent on the spatial alignment of the takeover of regional heads. Keywords: Spatial Policy, Interests and Influential Actors, Spatial Politics. 
Abstrak: Kabupaten Pandeglang Provinsi Banten telah menetapkan Perda No. 03 tahun 2011 tentang Tata Ruang Kabupaten Pandeglang 2011-2031. Pasca implementasi Perda tersebut belum berdampak pada pembangunan Kabupaten Pandeglang. Penelitian ini bertujuan untuk menganalisis aktor yang berperang dan berpengaruh dalam implementasi Perda RTRW. Penelitian ini menggunakan data primer berupa observasi, angket dan wawancara serta data sekunder berupa dokumen terkait kebijakan tata ruang. Pendekatan yang digunakan deskriptif kualitatif, dengan alat analisis stakeholder dan Content Analysis. Hasil penelitiannya adalah aktor yang berkepentingan dan berpengaruh dalam implementasi kebijakan tata ruang di Kabupaten Pandeglang adalah Bupati. Adapun instansi yang memiliki kepentingan dan pengaruh besar dalam kebijakan tata ruang adalah Bappeda, Dinas Pekerjaaan Umum dan Penataan Ruang, Dinas Penanaman Modal dan Pelayanan Perizinan Terpadu Satu Pintu. Selanjutnya, Dinas Lingkungan Hidup, Dinas Perikanan, Dinas Pariwisata, Dinas Pertanian, Dinas Perindustrian dan Perdagangan, Dinas Pemukiman, Kawasan Pemukiman dan Pertanahan, Komisi I DPRD Pandeglang, Dinas Perhubungan dan Satuan Polisi Pamong Praja. Pemain kunci atau key player dalam implementasi kebijakan adalah Bupati dan Dinas/Badan yang terkait. Adapun aktor yang memiliki kepentingan kecil dan pengaruhnya besar dalam kebijakan tata ruang di Pandeglang, yaitu Investor, Wartawan, LSM dikategorikan ke dalam Contest Setter (pendukung). Adapun aktor yang memilik kepentingan dan pengaruh kecil adalah media massa sehingga dikategorikan sebagai crowd (pengikut lain). Implementasi kebijakan tata ruang sangat tergantung keberpihakan tata ruang dari pengambil kebijakan yaitu kepala daerah sehingga kebijakan tata ruang merupakan aspek politik bukan aspek teknis.

Kata kunci : Kebijakan Tata Ruang, Aktor Berkepentingan dan Berpengaruh, Politik Tata Ruang 


\section{PENDAHULUAN}

Perencanaan ruang merupakan proses penyusunan rencana tata ruang untuk meningkatkan kualitas lingkungan hidup, manusia, dan kualitas pemanfaatan ruang (Tusin 2004). Fungsi penataan ruang menurut Rustiadi dan Hadi (2004), memiliki tiga urgensi, yaitu: pertama; optimalisasi pemanfaatan sumberdaya (prinsip produktifitas dan efisiensi), kedua; alat dan wujud distribusi sumberdaya (prinsip pemerataan, keberimbangan,dan keadilan), dan ketiga; keberlanjutan (prinsip sustainability). Pemerintah telah menetapkan kebijakan tata ruang berupa Undang-Undang (UU) No. 26 tahun 2007 tentang Penataan Ruang yang mewajibkan pemerintah daerah untuk menyusun Rencana Tata Ruang dan Wilayah (RTRW) di daerah masing-masing.

Pemerintah Daerah Kabupaten Pandeglang telah menetapkan Peraturan Daerah (Perda) No. 3 tahun 2011 tentang Rencana Tata Ruang dan Wilayah Kabupaten 20112031. Sejak ditetapkan Perda RTRW 2011-2016, Bupati Pandeglang telah mengeluarkan regulasi pelaksanaanya melalui Peraturan Bupati (Perbup) No. 36 tahun 2012 tentang Izin Pemanfaatan Ruang yang telah direvisi menjadi Peraturan Bupati No. 27 tahun 2015 tentang Izin Prinsip Pemanfaatan Ruang dengan harapan dapat mempermudah proses perizinan pemanfaatan ruang bagi para investor. Bupati Pandeglang juga telah menetapkan SK Bupati No. 50/Kep. 55-Huk/2015 tentang Pembentukan Badan Koordinasi Penataan Ruang Daerah (BKPRD) sebagai badan yang ditugaskan untuk memberikan rekomendasi perizinan pemanfaatan ruang sebagai bahan pertimbangan bagi Bupati Pandeglang dalam mengambil keputusan.

Dalam kurun waktu lima tahun implementasi Perda RTRW Kabupaten Pandeglang banyak pihak yang berkepentingan dan mempengaruhi terhadap implementasi kebijakan tata ruang di Kabupaten Pandeglang. Potensi sumber daya alam yang berlimpah menjadi salah satu faktor yang mempengaruhi masuknya kepentingan dari pihak tertentu sebagaimana pendapat Kadir W et al. (2013). Faktor yang lain adalah karena adanya benturan kepentingan antar sektor seperti pertambangan dan lingkungan hidup (Imran 2013) dan konflik kepentingan antar aktor dalam mengkonstruksi ruang (Aminah 2015). Kondisi ini disebabkan masih rendahnya kemampuan dan keikhlasan dalam menempatkan kepentingan sektor dan wilayah dalam kerangka penataan ruang (Ginting 2011).

Fenomena tarik menarik kepentingan dan pengaruh dalam kebijakan menjadikan setiap aktor yang terlibat kebijakan tata ruang berupaya untuk mengejar orientasi baik yang bersifat individual maupun kelembagaan sehingga terjadi konflik kepentingan dalam kebijakan publik (Prasetyo 2012). Hal tersebut karena ruang merupakan produk politik dan mengakibatkan praktik tata ruang tidak pernah bebas dari keberpihakan aktor yang membuat regulasi tata ruang (aminah 2015) sehingga pembangunan daerah tak lepas dari adanya perebutan sumber daya dari para elit politik lokal (Dawkin 2003). Hamid (2010) menjelaskan adanya peran dan tarikan kepentingan dari jawara, pengusaha lokal dan politisi dalam pembangunan di Provinsi Banten termasuk Kabupaten Pandeglang. Oleh 
karena itu, sangat penting diteliti tentang aktor yang berkepentingan dan berpengaruh dalam implementasi kebijakan tata ruang dan bagaimana peran dan keberpihakan dari deciton maker (Bupati Pandeglang) dalam kebijakan tata ruang di Kabupaten Pandeglang karena kebijakan tata ruang menurut Thondhlana (2015) dan Wanga et al (2014) sangat tergantung dari good will dan keberpihakan kebijakan pemerintah terhadap ruang.

\section{Tujuan dan Kegunaan Penelitian}

Tujuan penelitian ini adalah a) untuk mengidentifikasi pihak terkait (stakeholder) yang terlibat dalam implementasi Perda RTRW Kabupaten Pandeglang. b) Untuk mengetahui kepentingan dan pengaruh pihak terkait (stakeholder) dalam implementasi kebijakan tata ruang di Kabupaten Pandeglang. 3) Merumuskan peran pihak terkait (stakeholder) dalam implementasi kebijakan tata ruang di Kabupaten Pandeglang. Penelitian ini juga untuk membuktikan bahwa implementasi kebijakan tata ruang adalah political aspect bukan technical aspect. Penelitian ini diharapkan dapat memberikan masukan bagi pemerintah daerah Kabupaten Pandeglang dalam menempatkan stakeholder secara tepat dalam kebijakan tata ruang.

\section{TINJAUAN PUSTAKA}

Kajian tentang aktor yang mempengaruhi tentang kebijakan tata ruang tak lepas dari Teori politik tata ruang dicetuskan oleh Lavebre (1991). Dalam bukunya berjudul The production of space, Ia menjelaskan tidak ada ruang yang ideal karena ruang menurut masyarakat kapitalis modern merupakan arena pertarungan yang tidak akan pernah selesai diperebutkan. Seluruh pihak yang berkepentingan akan berusaha mendominasi pemanfaatan ruang dan mereproduksi semua pengetahuan untuk mempertahankan hegemoni mereka atas pemanfaatan ruang tersebut. Dampaknya adalah ruang bersama (common space) menyesuaikan kepentingan kapital dalam rangka menjamin hubungan produksi dan reproduksi yang bersifat kapitalistik sehingga produksi ruang secara spasial akan mempengaruhi mentalitas seluruh pihak yang berkepentingan sehingga menciptakan relasi produksi antara ruang secara spasial dengan masyarakat.

Kajian Lavebre (1991) mengerucut pada tiga konsep ruang dikaitkan dengan bagaimana ruang sosial dihasilkan. Pertama, praktik spasial (Spatial Practices). Praktik spasial tidak terlepas dari keterlibatan seluruh masyarakat yang memiliki hubungan atas kepemilikan ruang. Oleh karena itu, kohesi sosial atas suatu ruang ditentukan oleh kompetensi dan tingkat kinerja atas pemakaian ruang (fisik atau material). Kedua, representasi ruang yang sangat tergantung pada hubungan produksi dan tatanan yang memaksakan pola hubungan tertentu pada pemanfaatan ruang. Representasi ruang sangat terkait dengan pengetahuan, tanda-tanda, bahkan sikap hubungan yang bersifat frontal. Ketiga, ruang representasional. Ketiga konsep tersebut mendorong ruang secara nyata 
hidup (lived space) serta berkaitan secara langsung dengan berbagai bentuk pencitraan serta simbol yang terkait sehingga para aktor dalam ruang saling berinteraksi. Interkasi aktor dalam ruangan sangat terkait dengan tarikan kepentingan aktor terhadap sumberdaya.

Sumberdaya didefinisikan sebagai semua potensi yang disediakan oleh alam dan manusia baik dalam bentuk tanah, bahan mentah, modal, tenaga kerja, keahlian, keindahan alam maupun sosial budaya. Adisasmita (2006) menjelaskan bahwa Potensi sumberdaya tersebut diharapkan dapat meningkatkan kesejahteraan masyarakat di daerah yang bersangkutan. Studi Larsen (2006) memberikan gambaran bahwa Norwegia menjadi salah satu contoh negara yang mampu mengoptimalkan sumber daya mineralnya sehingga berdampak bagi kesejahteraan masyarakat dan perekonomian negara secara makro.

\section{METODE PENELITIAN}

\section{Lokasi dan Waktu Penelitian}

Lokasi penelitian dilaksanakan di Kabupaten Pandeglang Provinsi Banten. Waktu peneltian dari bulan Juni 2016 - Desember 2017.

\section{Pengumpulan data}

Data primer dikumpulkan dengan observasi, angket dan wawancara terbuka terhadap semua stakeholder yang yang terlibat dan berperan dalam proses implementasi Perda RTRW No.03 tahun 2011. Observasi dilakukan untuk melihat pihak yang terlibat dalam implementasi perda RTRW dan angket dan wawancara terbuka dimaksudkan untuk mengetahui aktor yang berkepentingan serta berpengaruh dalam implementasi kebijakan tata ruang di Kabupaten Pandeglang. Angket dan wawancara terbuka dilakukan pada informan kunci dengan menggunakan teknik sampling purposive. Informan kunci tersebut berasal dari Dinas yang terlibat dalam implementasi kebijakan tata ruang, seperti Bappeda, Dinas Pekerjaaan Umum dan Penataan Ruang, Dinas Penanaman Modal dan Pelayanan Perizinan Terpadu Satu Pintu, Dinas Lingkungan Hidup, Dinas Perikanan, Dinas Pariwisata, Dinas Pertanian, Dinas Perindustrian dan Perdagangan, Dinas Pemukiman, Kawasan Pemukiman dan Pertanahan, Komisi I DPRD Pandeglang, Dinas Perhubungan dan Satuan Polisi Pamong Praja, Investor, Wartawan, LSM dan Media Massa. Penelitian ini juga menggunakan data sekunder berupa dokumen, kebijakan yang terkait dengan kebijakan tata ruang di Kabupaten Pandeglang.

\section{Analisis Data}

Analisis yang digunakan dalam penelitian ini menggunakan pendekatan deskriptif kualitatif, dengan menggunakan analisis stakeholder dan content analysis. Dua alat 
analisis tersebut diharapkan dapat menggambarkan aktor yang berkepentingan dan pengaruh dalam implementasi kebijakan tata ruang di Kabupaten Pandeglang.

\section{PEMBAHASAN}

\section{Identifikasi Aktor dalam Implementasi Kebijakan Tata Ruang di Kabupaten Pandeglang}

Langkah pertama dalam penelitian ini, peneliti melakukan identifikasi aktor yang berperan dan berpengaruh dalam kebijakan RTRW Kabupaten Pandeglang. Untuk mengetahui aktor tersebut, peneliti melakukan penelaahan dokumen baik Perda RTRW, Aturan turunannya berupa Peraturan Bupati (Perbup) No. 36 tahun 2012 tentang Izin Pemanfaatan Ruang yang telah direvisi menjadi Peraturan Bupati No. 27 tahun 2015 tentang Izin Prinsip Pemanfaatan Ruang, SK Bupati No. 50/Kep. 55-Huk/2015 tentang Pembentukan BKPRD, Perda No 6 tahun 2016 tentang Pembentukan dan Susunan Perangkat Daerah Kabupaten Pandeglang serta Peraturan Bupati tentang Kedudukan, Susunan Organisasi, Rincian Tugas dan Fungsi serta Tata Kerja Dinas dan Badan di Kabupaten Pandeglang. Dokumen tersebut ditelaah dengan content analysis untuk dianalisis aktor yang terlibat dalam implementasi kebijakan tata ruang di Kabupaten Pandeglang. Penulis juga melakukan wawancara untuk memperkuat peran aktor yang lebih akurat dalam implementasi kebijakan tata ruang di Pandeglang. Berdasarkan studi dokumen dan wawancara tersebut, teridentifikasi aktor yang terlibat dalam kebijakan tata ruang di Pandeglang adalah Badan Perencanaan Daerah (Bappeda); Dinas Penanaman Modal Pelayanan Terpadu Satu Pintu (PMPTSP); Dinas Lingkungan Hidup; Dinas Pekerjaan Umum dan Penataan Ruang; Dinas Perikanan, Satpol Pamong Praja; Dinas Pariwisata; Dinas Pertanian; Dinas Pemukiman, Kawasan Pemukiman dan Pertanahan; Dinas Perhubungan, Dinas Perindustrian, Perdagangan, dan Energi Sumber Daya Mineral; Investor (Pelaku Bisnis yang telah melakukan perizinan), Lembaga Swadaya Masyarakat (LSM), Media Massa, Akademisi, DPRD Komisi I, Bupati Pandeglang.

\section{Analisis Kepentingan dan Pengaruh Stakeholder dalam Kebijakan Tata Ruang di Kabupaten Pandeglang}

Analisis aktor yang berperan dan berpengaruh dalam implementasi kebijakan tata ruang di Kabupaten Pandeglang Provinsi Banten dilakukan analisis stakeholder. Output analisis adalah klasifikasi pihak yang terkait dengan kebijakan tata ruang dalam katagori subyek (subjects), pemain kunci (key players), pendukung (contest setter), pengikut lain (crowd) berdasarkan tingkat kepentingan dan pengaruhnya dalam kebijakan tata ruang di Kabupaten Pandeglang.

Berdasarkan tingkat kepentingan dalam implementasi kebijakan tata ruang di Kabupaten Pandeglang, aktor yang paling berkepentingan sangat besar dalam 
implementasi kebijakan tata ruang di Kabupaten Pandeglang berdasarkan kriteria keterlibatan, manfaat, kewenangan, program kerja dan tingkat ketergantungan sumber daya adalah Dinas Lingkungan Hidup, Dinas Pekerjaan Umum dan Penataan Ruang, Badan Perencaaan Daerah, Dinas Perikanan dan Bupati Kabupaten Pandeglang selaku pengambil kebijakan penataan ruang di Kabupaten Pandeglang sesuai dengan tabel 1.

Tabel 1 Tingkat Kepentingan Stakeholder terhadap Kebijakan Tata Ruang

\begin{tabular}{|l|l|l|l|}
\hline No & Aktor & Skor Nilai & Keterangan \\
\hline 1 & Bappeda Pandeglang & 4,6 & Sangat Tinggi \\
\hline 2 & Dinas Pertanian Kabupaten Pandeglang & 4,4 & Sangat Tinggi \\
\hline 3 & $\begin{array}{l}\text { Dinas Pekerjaan Umum dan Penataan } \\
\text { Ruang Pandeglang }\end{array}$ & 4,6 & Sangat Tinggi \\
\hline 4 & $\begin{array}{l}\text { Dinas Perumahan, Kawasan Pemukiman } \\
\text { dan Pertanahan Pandeglang }\end{array}$ & 4 & Tinggi \\
\hline 5 & $\begin{array}{l}\text { Dinas Penanaman Modal Pelayanan } \\
\text { Terpadu Satu Pintu }\end{array}$ & 4,4 & Sangat Tinggi \\
\hline 6 & Dinas Perikanan & 4,6 & Sangat Tinggi \\
\hline 7 & $\begin{array}{l}\text { Dinas Perindustrian, Perdagangan dan } \\
\text { Energi Sumber Daya Mineral }\end{array}$ & 4,2 & Sangat Tinggi \\
\hline 8 & Dinas Pariwisata & 4,2 & Sangat Tinggi \\
\hline 9 & Satuan Polisi Pamong Praja & 2,8 & Sedang \\
\hline 10 & DPRD Kabupaten Pandeglang & 3,8 & Tinggi \\
\hline 11 & Dinas Perhubungan & 3,2 & Tinggi \\
\hline 12 & Dinas Lingkungan Hidup & 4,6 & Sangat Tinggi \\
\hline 13 & Bupati & 4,6 & Sangat Tinggi \\
\hline 14 & Akademisi & 1,8 & Rendah \\
\hline 15 & LSM & 2,8 & Sedang \\
\hline 16 & Investor & 2,2 & Sedang \\
\hline
\end{tabular}

Sumber : Data Primer, diolah 2017

Keterangan :

$0-1,0$ : sangat rendah;

1,1-2,0: rendah

2,1-3,0 : Sedang;

3,1-4,0: tinggi

$4,1-5,0$ : sangat tinggi

Besarnya kepentingan dari Dinas perikanan adalah karena Kabupaten pandeglang memiliki potensi besar dalam pengembangan ekonomi perikanan masyarakat. Adapun Dinas Lingkungan hidup merupakan bagian dari tim perumus Rencana Tata Ruang dan Rencana Wilayah Kabupaten Pandeglang sesuai dengan dan memberikan dokumen Kajian Lingkungan Hidup Strategis (KLHS) sebagai persyaratan pengajuan Perda RTRW. Dinas Lingkungan Hidup juga sesuai dengan Peraturan Bupati No. 01 tahun 2017 memiliki tugas 
untuk terlibat secara langsung dalam implementasi kebijakan, pengawasan kebijakan tata ruang dan penindakan atau sanksi terhadap perusahaan yang tidak mengindahkan analisis dampak lingkungan. Badan Perencanaan Pembangunan Daerah memiliki kepentingan besar sebagi institusi di Kabupaten Pandeglang yang menjadi koordinator dalam penyusunan dan revisi RTRW serta desain kebijakan tata ruang di Kabupaten Pandeglang. Dinas Pekerjaan Umum dan Penataan Ruang (PUPR) adalah instansi yang paling bertanggung jawab dalam implementasi RTRW sehingga investor dalam mengajukan izin harus meminta rekomendasi dari Dinas PUPR tentang Izin Prinsip Panataan Ruang. PUPR menjadi instansi yang ditunjuk Pemda Kabupaten Pandeglang koorinator dalam bidang evaluasi pemanfaatan ruang pada Badan Koordinasi Penataan Ruang Daerah (BKPRD). Aktor yang paling besar kepentingannya implementasi kebijakan tata ruang di Kabupaten pandeglang adalah Bupati Kabupaten Pandeglang. Besarnya kepentingan tersebut bisa terlihat dari unsur pelibatan kebijakan tata ruang baik dari sisi perencanaan, implementasi dan sanksi yang walaupun kewenangannya telah didelegasikan pada dinas terkait, dalam realitasnya tetap harus memperoleh persetujuan dari Bupati Pandeglang. Demikian juga pada unsur manfaat, bupati memberikan harapan besar agar kebijakan tata ruang memberikan dampak yang besar baik secara ekonomi, sosial dan lingkungan bagi pembangunan yang berkelanjutan di Kabupaten Pandeglang. Bupati Kabupaten Pandeglang memiliki weweangan yang besar terhadap desain pembangunan Kabupaten Pandeglang sehingga Visi Bupati yang terpilih dalam Pemilihan Kepala Daerah menjadi Visi Kabupaten Pandeglang dan dimasukkan dalam Rencana Pembangunan Jangka Menengah Kabupaten Pandeglang 2016-2021. Sumber daya wilayah menjadi perhatian Bupati Pandeglang dalam kebijakan tata ruang. Dengan kewenangan yang besar maka kepentingan bupati Pandeglang dalam menentukan kebijakan tata ruang juga besar hanya progam kerja bupati dalam membangun pandeglang masih dikatagori cukup prioritas karena banyak tugas dan tanggung jawab yang dijalankan Bupati Pandeglang selain tata ruang.

Tingkat pengaruh dalam kebijakan tata ruang di Kabupaten Pandeglang, dianalisis dengan indikator aturan pengelolaan kebijakan tata ruang, kemampuan interaksi sumber daya manusia, peran dan partisipasi dalam kebijakan tata ruang, kekuatan kepribadian, kapasitas/kondisi sumber daya yang dimiliki. Berdasarkan indikator tersebut, dinas/instansi yang memiliki pengaruh besar dalam kebijakan implementasi tata ruang di Kabupaten Pandeglang adalah Bappeda, Dinas PUPR dan PMPTSP. Ketiga dinas ini memiliki pengaruh yang besar sebagaimana amanah Peraturan Bupati No. 36 tahun 2012 tentang Izin Pemanfaatan Ruang yang telah direvisi menjadi Peraturan Bupati No. 27 tahun 2015 tentang Izin Prinsip Pemanfaatan Ruang. Ketiga instansi tersebut termasuk dalam Badan Koordinasi Penataan Ruang Daerah (BKPRD) sesuai SK Bupati No. 50/Kep. 55-Huk/2015 tentang Pembentukan BKPRD. 
Tabel 2 Tingkat Pengaruh Stakeholder terhadap Kebijakan Tata Ruang

\begin{tabular}{|l|l|l|l|}
\hline No & Aktor & Skor Nilai & Keterangan \\
\hline 1 & Bappeda Pandeglang & 4,6 & Sangat Tinggi \\
\hline 2 & Dinas Pertanian Kabupaten Pandeglang & 3,2 & Tinggi \\
\hline 3 & $\begin{array}{l}\text { Dinas Pekerjaan Umum dan Penataan Ruang } \\
\text { Pandeglang }\end{array}$ & 4,6 & Sangat Tinggi \\
\hline 4 & $\begin{array}{l}\text { Dinas Perumahan, Kawasan Pemukiman dan } \\
\text { Pertanahan Pandeglang }\end{array}$ & 3,6 & Tinggi \\
\hline 5 & $\begin{array}{l}\text { Dinas Penanaman Modal Pelayanan Terpadu } \\
\text { Satu Pintu }\end{array}$ & 4,6 & Sangat Tinggi \\
\hline 6 & Dinas Perikanan & 3,8 & Tinggi \\
\hline 7 & $\begin{array}{l}\text { Dinas Perindustrian, Perdagangan dan Energi } \\
\text { Sumber Daya Mineral }\end{array}$ & 3,6 & Tinggi \\
\hline 8 & Dinas Pariwisata & 3,4 & Tinggi \\
\hline 9 & Satuan Polisi Pamong Praja & 3,6 & Tinggi \\
\hline 10 & DPRD Kabupaten Pandeglang & 3,6 & Tinggi \\
\hline 11 & Dinas Perhubungan & 3,6 & Tinggi \\
\hline 12 & Dinas Lingkungan Hidup & 4,2 & Sangat Tinggi \\
\hline 13 & Bupati & 3,8 & Sangat Tinggi \\
\hline 14 & Akademisi & 3,6 & Tinggu \\
\hline 15 & LSM & Tinggi \\
\hline 16 & Investor & & \\
\hline Sumg & Der Data Primer, diang & \\
\hline
\end{tabular}

Sumber : Data Primer, diolah 2017

Keterangan :

0 - 1,0 : sangat rendah;

1,1-2,0: rendah

2,1-3,0 : Sedang;

3,1-4,0: tinggi

$4,1-5,0$ : sangat tinggi

Dalam Perbup No. 27 tahun 2015 tentang Izin Prinsip Pemanfaatan Ruang (IPPR) mengatur kewenangan tiga instansi tersebut, yaitu :

A. Dinas PUPR yang berperan dalam :

1. Memproses perizinan yang tidak diwajibkan Amdal (UKL-UPL).

2. Kabid Penataan ruang sebagai ketua pokja pemanfaatan ruang dan 
pengendalian pemanfataan ruang melakukan pembahasan permohonan IPRR yang masuk kategori wajib amdal.

3. Menjadi tim teknis penilaian kesesuain tata ruang berdasarkan SK Kepala Dinas PUPR.

B. Bappeda berperan sebagai :

1. Berperang aktif sebagai anggota Pokja pemanfaatan dan pengendalian pemanfaatan ruang BKPRD

2. Selaku sekretariat BKPRD :

a. Menyiapkan pelaksanaan rapat pembahasan permohonan oleh Pokja Pemanfaatan dan Pengendalian Pemanfaatan Ruang

b. Melakukan proses pemarafan rekomendasi BKPRD (Ketua sekretariat BKPRD, sekretaris BKPRD, Ketua Pokja Pemanfaatan dan Pengendalian Pemenfaatan Ruang BKPRD)

c. Memproses penandatangan rekomendasi BKPRD kepada ketua BKPRD

d. Meregister dan memberi nomer terhadap rekomendasi BKPRD

e. Menyampaikan rekomendasi BKPRD yang telah selesai kepada Dinas Penanam Modal Pelayanan Satu Pintu dan Perizinan Terpadu.

C. Dinas Penanaman Modal Pelayanan Terpadu Satu Pintu memiliki peran sebagai berikut :

1. Pemeriksaan administrasi terhadap kelengkapan persyaratan pengajuan IPPR

2. Proses pemilahan yang wajib Amdal, UKL-UPL dan SPPL atas dasar pertimbangan dan masukan dari tim teknis perizinan

3. Menjamin legalitas berkas permohonan dari segi pemilik, keabsahan alamat dan validitas surat-surat berharga lainnya

4. Menerima dan melengkapi berkas yang tidak lengkap yang diterima BKPRD

5. Meneruskan berkas yang lengkap ke BKPRD dan Dinas PUPR

6. Menerima laporan kemajuan usaha setiap enam bulan sekali dari pemegang IPPR

7. Memberikan teguran tertulis kepada pemegang IPPR yang tidak menyampaikan laporan kemajuan enam bulan sekali dari pemegang IPPR

8. Menerbitkan persetujuan/perolehan permohonan perpanjangan IPPR setelah mendapat rekomendasi dari BKPRD dan disetujui bupati selambat-lambatnya 30 hari kerja sejak diterimanya permohonan dinyatakan lengkap.

Kewenangan ketiga instansi tersebut memiliki pengaruh dalam kebijakan tata ruang di Kabupaten Pandeglang tapi kebijakan ahirnya tetap berdasarkan keputusan bupati sehingga kebijakan tata ruang sangat tergantung dari decation maker dan merupakan political aspect, artinya sangat tergantung dari kebijakan serta good will dari Bupati Pandeglang. 


\section{Pemetaan Aktor yang terlibat dalam Implementasi Kebijakan Tata Ruang di Kabupaten Pandeglang}

Berdasarkan tingkat kepentingan dan pengaruh stakeholder pada kebijakan tata ruang di Kabupaten Pandeglang, maka aktor yang terlibat dalam kebijakan tata ruang di Kabupaten Pandeglang dapat dikategorikan pada :

1. Stakeholder yang memiliki kepentingan dan pengaruh besar dalam kebijakan tata ruang di Kabupaten Pandeglang adalah Dinas PUPR, Bappeda, Dinas PMPTSP, Dinas Lingkungan Hidup, Dinas Perikanan, Dinas Pertanian, Dinas Pariwisata, Dinas Perindustrian, Perdangan dan Energi Sumber Daya Energi Mineral, Dinas Perumahan, Kawasan Pemukiman dan Pertanahan, Dinas Perhubungan, Satpol PP, DPRD Kabupaten Pandeglang. Stakeholder yang memiliki kepentingan dan pengaruh yang paling besar adalah Bupati Pandeglang karena seluruh arah dan kebijakan tata ruang sangat tergantung dari Bupati. Seluruh aktor tersebut dikategorikan ke dalam pemain kunci (key Players).

2. Stakeholder yang memiliki kepentingan kecil dan pengaruh besar dalam kebijakan tata ruang di Kabupaten Pandeglang adalah Investor (Pelaku Bisnis yang melakukan investari dan mengurus perizinan tata ruang), Akademisi yang konsen dan memberikan kontribusi pemikiran dalam kebijakan tata ruang di Kabupaten Pandeglang dan Lembaga Swadaya Masyarakat (LSM) yang memberikan perhatian husus pada kebijakan tata ruang di Kabupaten Pandeglang. Aktor yang masuk dalam kriteria tersebut dikategorikan ke dalam aktor pendukung (Contest Setter).

3. Dalam kebijakan tata ruang di Kabupaten Pandeglang aktor yang termasuk ke dalam kategori subyek (subjects), yaitu tidak aktor yang memiliki kepentingan besar dan pengaruh kecil sedangkan aktor yang masuk dalam kategori lain (Crowd) yang memiliki kepentingan dan pengaruh yang kecil adalah wartawan (media massa).

Klasifikasi stakeholder yang memeliki kepentingan dan berpengaruh dalam kebijakan tata ruang di Kabupaten Pandeglang dapat digambarkan pada Tabel 3

Tabel 3 Analisis Stakeholder dalam Kebijakan Tata Ruang di Pandeglang

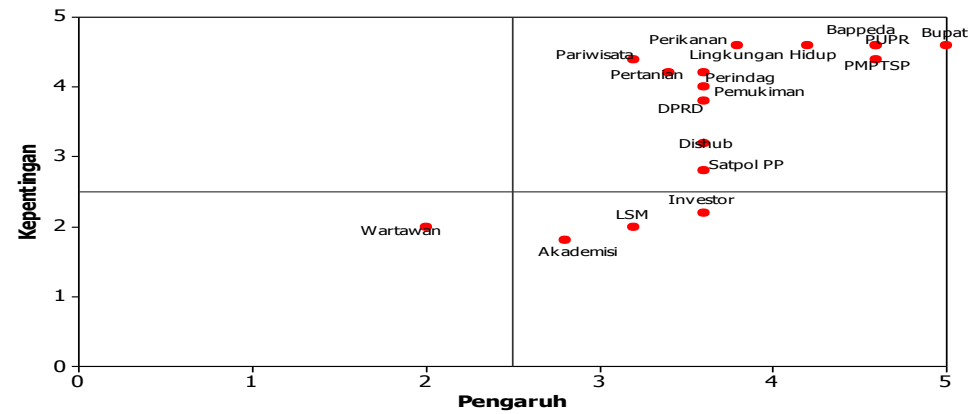


Sumber: data primer, diolah 2017

Gambar 1 Analisis Stakeholder dalam Kebijakan Tata Ruang di Pandeglang

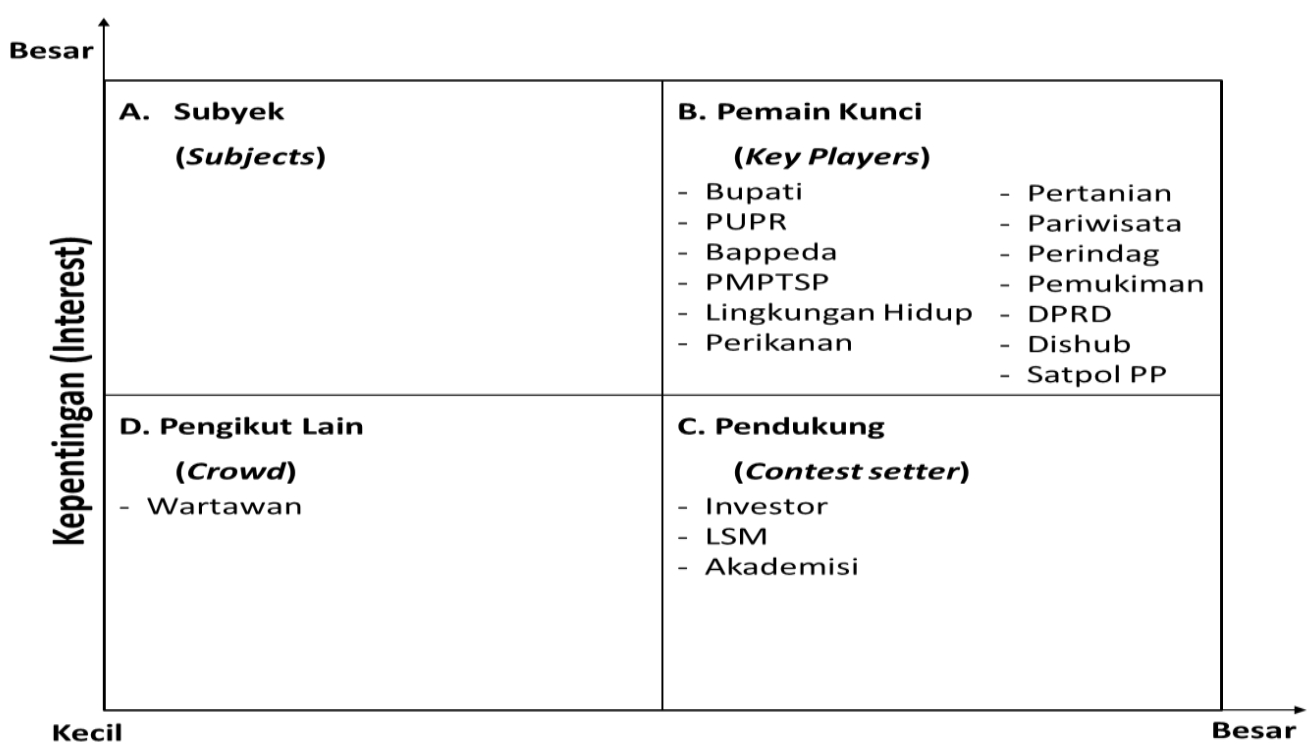

Sumber: data primer, diolah 2017

Berdasarkan klasifikasi analisis stakeholder tersebut, semua responden menjelaskan bahwa keputusan akhir dari kebijakan tata ruang di Kabupaten Pandeglang berada di Bupati Pandeglang (Wawancara seluruh stakeholder). Dalam aspek perencanaan, kebijakan tata ruang termasuk rencana revisi RTRW Kabupaten Pandeglang, Bupati Pandeglang berperan membentuk tim Peninjauan Kembali RTRW (RK RTRW) Kabupaten Pandeglang. Pada bulan Oktober-Desember 2016 Tim PK RTRW telah melakukan kajian dan hasil kajiannya merekomendasikan adanya revisi RTRW. Hasil kajian tersebut telah disampaikan ke Bupati Pandeglang melalui Pelaksana tugas (Plt) Sekda Ferry Hasnaudin, SH (Wawancara dengan Bappeda 2016).

Dalam implemenasi kebijakan tata ruang, Bupati telah melakukan perubahan proses izin pemanfaatan ruang yang semula mengacu pada Peraturan Bupati (Perbup) No. 36 tahun 2012 tentang Izin Pemanfaatan Ruang, telah direvisi menjadi Peraturan Bupati No. 27 tahun 2015 tentang Izin Prinsip Pemanfaatan Ruang (IPPR), yang berimplikasi pada kemudahan perizinan pemanfaatan ruang, diantara kemudahan tersebut adalah :

a) IPPR tidak diperlukan untuk usaha/kegiatan yang luas pemanfaatan tanahnya dibawah 1 Hektar dan/atau kegiatan yang masuk kedalam kategori wajib menyusun Surat Pernyataan Pengelolaan Lingkungan (SPPL).

b) IPPR tidak diperlukan bagi orang/badan/perusahaan yang tanah untuk melaksanakan rencana penanaman modalnya adalah tanah yang sudah dipunyai oleh orang/badan/ perusahaan yang bersangkutan, dengan ketentuan bahwa tanah- 
tanah tersebut terletak di lokasi yang menurut RTRW, diperuntukkan bagi penggunaan yang sesuai dengan rencana penanaman modal yang bersangkutan.

c) Kegiatan yang tidak memerlukan rekomendasi dari BKPRD adalah kegiatan usaha yang memiliki dampak lingkungan yang rendah sehingga tidak diwajibkan Analisis Dampak Lingkungan (Amdal). Pada kegiatan usaha tersebut cukup mendapat rekomendasi dari Dinas Pekerjaan Umum dan Penataan Ruang (PUPR), Usaha yang berada di dalam Kawasan Ekonomi Khusus (KEK) karena sudah diatur dalam regulasi tersendiri.

Kebijakan Bupati Pandeglang tersebut merupakan upaya pemerintah Kabupaten Pandeglang dalam menarik investor melakukan investasi dan mengembangkan perekonomian di Kabupaten Pandeglang. Bupati Pandeglang juga memiliki kewenangan dalam mengeluarkan izin dan mencabut izin sebagai Perbup. No. 27 tahun 2015 tentang Izin Prinsip Pemanfaatan Ruang (IPPR) sesuai pasal 9 (2C) :

"Kepala BPMPPTSP menerbitkan persetujuan atau perolehan permohonan IPPR setelah mendapat rekomendasi dari BKPRD dan setujui oleh Bupati selambatlambatnya dalam waktu (tiga puluh) hari kerja sejak diterimanya permohonan dinyatakan lengkap."

Besarnya kewenangan dan pengaruh kepala daerah, diindikasikan dengan terjadinya beberapa kebijakan yang berbeda karena pergantian kepala daerah akibat hasil Pemilihan Kepala Daerah di Kabupaten Pandeglang (Wawancara dengan LSM 2017). Perbedaan perlakuan kebijakan ini terjadi pada kasus perizinan investasi yang dilakukan oleh anak Perusahaan Mayora, yaitu PT. Tirta Fresindo Jaya (TFJ) di Kecamatan Cadasari Kabupaten Pandeglang.

1. Pada tahun 2013, Kepala Dinas Tata Ruang Kebersihan dan Pertamanan Kabupaten Pandeglang telah mengeluarkan keputusan No : 600/548.b/SKDTKP/XII/2013 tentang Persetujuan Site Plan Pembangunan Pabrik Minuman PT. Tirta Fresindo Jaya sehingga keluarlah perizinan PT. Tirta Fresiondo Jaya (Wawancara dengan Dinas PUPR dan Dinas Penanaman Modal dan Pelayan Terpada Satu Pintu)

2. Banyaknya penolakan dan demonstrasi dari LSM dan masyarakat di Kecamatan Cadasari Kabupaten Pandeglang, Bupati Pandeglang yang dijabat oleh Bapak Drs. Erwan Kurtubi, MM mengeluarkan Surat Keputusan Nomor : 0454/1669BPPT/2014 tanggal 21 November 2014 tentang Penghentian Kegiatan Investasi PT. Tirta Fresindo Jaya (Wawancara dengan Dinas PUPR dan Dinas Penanaman Modal dan Pelayan Terpada Satu Pintu, LSM dan akademisi)

3. Lokasi pabrik minuman PT. Tirta Fresiondo Jaya berada di Kampung Kramat Mushola, Desa Cadasari Kecamatan Cadasari Kabupaten Pandeglang bertentangan dengan Perda No. 3 tahun 2011 tentang RTRW Kabupaten Pandeglang dinyatakan "Pengembangan PPL sebagaimana dimaksud ayat (1) huruf a dengan fungsi utama 
sebagai pusat pemukiman dengan skala kegiatan antar desa meliputi : a. Desa Cadasari Kecamatan Cadasari. Desa Cadasari Kecamatan Cadasari termasuk ke dalam kawasan resapan air (Perda RTRW Pasal 31 ayat (1 dan 2) dan termasuk dalam kawasan lahan pangan berkelanjutan (LP2B) sesuai Pasal 39 ayat 6 Perda RTRW Kabupaten Pandeglang. (Dokumen RTRW Kabupaten Pandeglang)

4. Pada tahun 2016 di era kepemimpinan Bupati Irna Narulita, SE., MM dan Wakil Bupati Pandeglang, M. Tanto Arban, ME, Pemerintah Daerah Kabupaten Pandeglang mengumpulkan kembali manajemen PT. Tirta Fresiondo Jaya, warga dan tokoh masyarakat di Kecamatan Cadasari sehingga ahirnya diizinkan kembali beroperasinya perusahaan (Wawancara dengan Dinas Penanaman Modal dan Pelayan Terpada Satu Pintu, Dinas PUPR).

Beberapa fakta tersebut menunjukkan kebijakan tata ruang bukan merupakan aspek teknis yang hanya diputuskan berdasarkan kajian dan data yang tersedia, tapi lebih mengarah pada good will dan keberpihakan dari pengambil kebijakan dalam menentukan arah dan desain tata ruang suatu wilayah.

\section{PENUTUP}

1. Stakeholder yang memiliki kepentingan dan pengaruh besar dalam kebijakan tata ruang di Kabupaten Pandeglang adalah Dinas PUPR, Bappeda, Dinas PMPTSP, Dinas Lingkungan Hidup, Dinas Perikanan, Dinas Pertanian, Dinas Pariwisata, Dinas Perindustrian, Perdangan dan Energi Sumber Daya Energi Mineral, Dinas Perumahan, Kawasan Pemukiman dan Pertanahan, Dinas Perhubungan, Satpol PP, DPRD Kabupaten Pandeglang. Seluruh aktor tersebut dikategorikan ke dalam pemain kunci (key Players).

2. Stakeholder yang memiliki kepentingan dan pengaruh yang paling besar adalah Bupati Pandeglang karena seluruh arah dan kebijakan tata ruang sangat tergantung dari Bupati.

3. Stakeholder yang memiliki kepentingan kecil dan pengaruh besar dalam kebijakan tata ruang di Kabupaten Pandeglang adalah Investor (Pelaku Bisnis yang melakukan investari dan mengurus perizinan tata ruang), Akademisi yang konsen dan memberikan kontribusi pemikiran dalam kebijakan tata ruang di Kabupaten Pandeglang dan Lembaga Swadaya Masyarakat (LSM) yang memberikan perhatian husus pada kebijakan tata ruang di Kabupaten Pandeglang. Aktor yang masuk dalam kriteria tersebut dikategorikan ke dalam aktor pendukung (Contest Setter).

4. Dalam kebijakan tata ruang di Kabupaten Pandeglang aktor yang termasuk ke dalam kategori subyek (subjects), yaitu tidak aktor yang memiliki kepentingan besar dan pengaruh kecil sedangkan aktor yang masuk dalam kategori lain (Crowd) 
yang memiliki kepentingan dan pengaruh yang kecil adalah wartawan (media massa).

\section{SARAN}

1. Bupati Pandeglang sebagi key player utama dan penentuk kebijakan tata ruang di Kabupaten Pandeglang harus memberikan arah dan kebijakan tata ruang yang mendorong terciptanya tujuan untuk : pertama, optimalisasi pemanfaatan sumberdaya (prinsip produktifitas dan efisiensi), kedua; alat dan wujud distribusi sumberdaya (prinsip pemerataan, keberimbangan,dan keadilan), dan ketiga; keberlanjutan (prinsip sustainability).

2. Bupati perlu mengelola secara efektif konflik kepentingan antar aktor dan sektor dalam mengkonstruksi ruang dan menempatkan kepentingan kerangka kebijakan penataan ruang yang membawa kemajuan bagi daerah dan keberlanjutan pembangunan.

\section{DAFTAR PUSTAKA}

Abd. Kadir W., San Afri Awang, Ris Hadi Purwanto dan Erny Poedjirahajoe. 2013. Analisis Stakeholder Pengelolaan Taman Nasional Bantimurung Bulusaraung, Provinsi Sulawesi Selatan.. J Manusia dan Lingkungan 20 (1) : 11-21

Aminah, Siti. 2015. Konflik dan Kontestasi Penataan Ruang Kota Surabaya. J Masyarakat, $20(1): 59-79$

Badan Perencanaan Daerah (Bappeda) Kabupaten Pandeglang. 2016. Dokumen Evaluasi RTRW Kabupaten Pandeglang Kerjasama Bappeda Kabupaten Pandeglang-P4W LPPM IPB Bogor.

Dawkin CJ. 2003. Regional Development Theory: Conceptual Foundations, Classics Work, and Recent Development. J Planning Literature 18 (2): 146-157.

Ginting, D. 2011. Reformasi Hukum Tanah dalam Rangka Perlindungan Hak Atas Tanah Perorangan dan Penanaman Modal Dalam Bidang Agrobisnis. J Hukum Ius Quia Iustum, 18 (1) : 66. Fakultas Hukum Universitas Islam Indonesia Yogyakarta

Wijayanto, Hendra, 2017. Implementasi Kebijakan Ruang Terbuka Hijau Di Implementasi

Kebijakan Ruang Terbuka Hijau Di Kawasan Perkotaan (Studi Pengembangan Ruang Terbuka Hijau Di Kota Jakarta Utara)

Hamid A. 2010. Memetakan Aktor Politik Lokal Pasca Orde Baru: Studi Kasus Kiyai dan Jawara di Banten. J Politika Universitas Diponegoro I (2): 10-20. 
Hidayat S, Wijaya A. 2010. Pilkada dan Pergeseran Sistem Pembangunan Daerah: Studi Kasus di Provinsi Banten. Jakarta (ID): Lembaga Ilmu Pengetahuan Indonesia.

Imran, SY. 2013. Fungsi Tata Ruang Dalam Menjaga Kelestarian Lingkungan Hidup Kota Gorontalo. J Dinamika Hukum 13 (3) : 457-467.

Larsen ER. 2006. Escaping the Resource Curse and the Dutch Disease? When and Why Norway Cought Up and Forget Ahead of Its Neighbors. Journal of Economics and Sociology.

Lefebvre, H. 1991. The production of space (Vol. 142) Blackwell (UK): Oxford

Prasetyo B. 2012. Kajian Teoretik Karakter Kebijakan Publik. J Politik Indonesia 1 (1): 110

Rustiadi, E., \& Hadi, S. 2004. Pengembangan Agropolitan Sebagai Strategi Pembangunan Perdesaan dan Pembangunan Berimbang. Makalah Workshop Pengembangan Agropolitan Sebagai Strategi Pembangunan Perdesaan dan Wilayah Secara Berimbang. P4W-IPB dan P3PT. Bogor.

Thondhlan G. 2015. Land acquisition for and local livelihood implications of biofuel development in Zimbabwe. J Land Use Policy, 49: 11-19.

Tusin, GG. 2004. Pengaruh Kebijakan Politik Pembangunan terhadap Tata Ruang Kota (Studi Kasus : Kota Jakarta). J Nalars 3(2) : 46-59

Wanga J, Liu Y, Fang F, Li Y. 2014. Key issues of land use in China and implications for policy making. J Land Use Policy, 40: 6-12 